\title{
Historiando el origen del Ilustre Colegio Provincial de Practicantes de Huelva
}

\section{Historian the origin of the Ilustre Colegio Provincial of Practitioners of Huelva}

\section{Historiar as origens do College of Practitioners Provincial de Huelva}

Jose Eugenio Guerra-González'1, Diego José. Feria Lorenzo², Carmen María Martínez-Sánchez ${ }^{3}$

${ }^{1}$ Enfermero de Huelva. Máster en Ciencias de la Enfermería. Hospital Ntra. Sra. de Valme, Sevilla

${ }^{2}$ Enfermero. Licenciado en Historia. Profesor Titular de la Facultad de Enfermería Universidad de Huelva

${ }^{3}$ Enfermera. Máster en Nuevas tendencias asistenciales en Ciencias de la Salud. Hospital El Tomillar, Sevilla

Cómo citar este artículo en edición digital: Guerra-González, J.E., Feria Lorenzo, D.J., Martínez-Sánchez, C.Ma. Historiando el origen del Ilustre Colegio Provincial de Practicantes de Huelva. Cultura de los Cuidados (Edición digital) 18, 38. Disponible en: http://dx.doi.org/10.7184/cuid.2014.38.8>

Correspondencia: José Eugenio Guerra-González. C/Luis Romera Ojeda nº 12. 41500 Alcalá de Guadaira (Sevilla) Correo electrónico: ppguerra30@hotmail.com Recibido: 21/11/2013; Aceptado: 12/01/2014

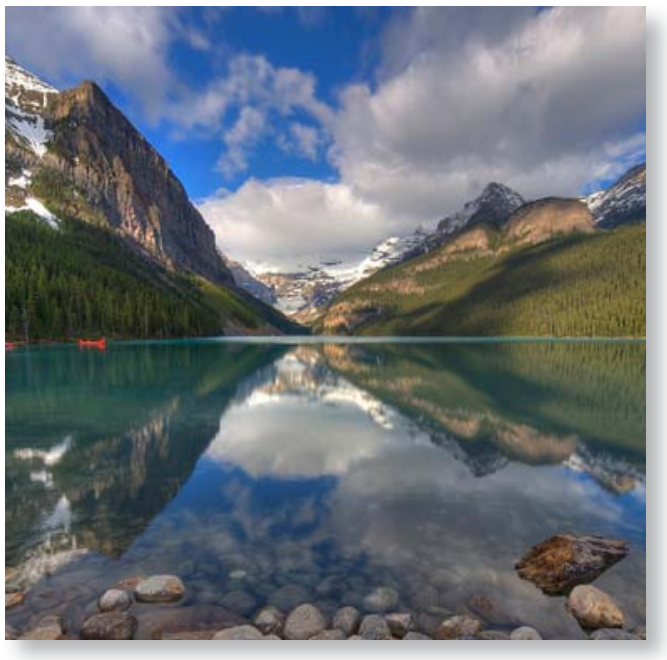

\section{ABSTRACT}

This article is about a document of utmost importance for the collegiate body nurse of Huelva extracted from book of proceedings of the Colegio Provincial of Practitioners of Sevilla (5-5-1909/19-8-1918), in which reference is made back in the year 1912 the need of referees in Seville but Huelva source they believe their own school in our province. A first attempt that bore no fruit, but so has and must not ignore it. Article chronicles the ardu- ous efforts in the run-up and the evolution of the research, the book of records of the Colegio Provincial of Practitioners of Sevilla (5-51909/19-8-1918) and analysis of the Act itself, i.e. mentions place celebration, participants, application of sanctions to not attending, approval of the minutes of the previous general and the last directive, application for admission in the collegiate institution internal economic balance, collegiate board, proposed appointment of delegate at this school in Huelva for the creation of a professional order, the entry into force of certain articles of the regulations -relief-. Finally, the authors carried out a personal reflection on the matter, i.e. research in History College of Nursing in Huelva.

Keywords: history, college nursing, centenary, commemoration.

\section{RESUMO}

Este artigo é sobre um documento muito importante para Huelva enfermeira colegiado tirada do Livro de Atos do Colégio Provincial de Praticantes de Sevilha (5-5-1909/19-81918), que remetido 1912 da necessidade de 
uma casa colegiada em Huelva Sevilla, mas criar sua própria escola em nossa província. A primeira tentativa não foi bem sucedida, mas tem e não devemos ignorar. $\mathrm{O}$ artigo narra as árduas negociações na véspera e no curso da investigação, a análise do Livro de Atas do Colégio de Médicos de Sevilha, 5-5-1909/198-1918 eo ato em si, é mencionada local de encontro, os participantes, e não sanções assistentes, a aprovação Lei Geral e do conselho de anteontem, pedido de adesão na instituição colegiada, o equilíbrio econômico interno, colegiado rejeitou, delegado nomeação deste College, em Huelva a criação de uma associação profissional e entrada em vigor de certos artigos do Regulamento de alívio. Finalmente, os autores realizar uma reflexão pessoal sobre o assunto, ou seja, investigar Colegiado de Enfermagem História de Huelva.

Palavras-chave: história, Escola de Enfermagem, comemoração do Centenário

\section{RESUMEN}

Este artículo versa sobre un documento de suma importancia para el ente colegial enfermero de Huelva extraído del Libro de Actas del Colegio Provincial de Practicantes de Sevilla (5-5-1909/19-8-1918), en el que se hace referencia allá por el año 1912 de la necesidad de que colegiados en Sevilla pero de origen onubense creen su propio Colegio en nuestra provincia. Un primer intento que no fructificó pero así consta y no debemos obviarlo. El artículo narra las arduas gestiones en los prolegómenos y en el devenir de la investigación, el análisis del Libro de Actas del Colegio de Practicantes de Sevilla, 5-5-1909/19-8-1918 y del Acta en sí, es decir menciona lugar de celebración, asistentes, aplicación de sanciones a no asistentes, aprobación del Acta general anterior y de la directiva última, solicitud de ingreso en la institución colegial, balance económico interno, colegiados cesados, propuesta de nombramiento de delegado de este Colegio en Huelva para la creación de un Colegio profesional y la entrada en vigor de determinados artículos del Reglamento -socorros-. Para finalizar, los autores realizan una reflexión personal al respecto, es decir investigar en Historia Colegial de Enfermera de Huelva.

Palabras clave: Historia, Colegio de Enfermería, Centenario.

\section{INTRODUCCIÓN}

\section{Arduas gestiones en los prolegómenos de esta Historia...}

El conocimiento documental de la existencia de iníciales gestiones para la creación del Colegio de Practicantes de la provincia de Huelva (Gallardo, 1999, 1993), hace que desde ese momento fuera un objetivo primordial a abordar oportunamente en un futuro no muy lejano por los autores. Continuadores de una línea de investigación en torno al estudio de otras fuentes, en este caso entes formales de la profesión, entiéndase Colegios, Consejos, Escuelas enfermeras etc., como otros autores (Velandia, 2009), (Oguisso, 2012), (Ruiz, 2011, 2012), surge este trabajo con expectativas de aportar conocimiento a la profesión. Nuestras gestiones se inician con una autorización fechada en el mes de mayo del año 2009, del Presidente del Colegio de Huelva D. Gonzalo García Domínguez a su homónimo en el Colegio de Sevilla, D. José María Rueda Segura en el que se informa de la pretensión de los autores -colegiados onubenses-, de realizar la Historia del Colegio Onubense para conmemorar el Centenario de esta institución colegial en 2012. A partir de este momento se suceden durante varios meses, intentos de citas tele- 
fónicas y varias visitas a la sede colegial hispalense con encuentros con el Presidente. En una primera reunión el 29 de Octubre de 2010 con el Secretario se logra localizar en su despacho no sin dificultades y disponer del Libro de Actas del Colegio Provincial de Practicantes de Sevilla (5-5-1909/19-8-1918) (Colegio Provincial de Practicantes de Sevilla, 1909). Un hecho resultó crucial, la entrega de premios del XXVII Certamen Nacional de Investigación de Enfermería del Ilustre Colegio de Enfermería de Sevilla en el que se coincidió con la Directiva colegial hispalense, acaso la última oportunidad para concretar una cita y poder examinar el Libro de Actas. En fecha señalada, 19 de Junio de 2012, la cita con el Secretario del Colegio de Enfermería de Sevilla D. Carmelo Gallardo Moraleda era una realidad y después de buscar unos interminables minutos en su despacho podía mostrar el Libro de Actas del Colegio Provincial de Practicantes de Sevilla (5-5-1909/19-8-1918), en esta ocasión para devorarlo con un exhaustivo análisis. Así en la trigésima sesión colegial registrada, con fecha 1 de Julio de 1912 aparece en el Libro de Actas del Colegio Provincial de Practicantes de Sevilla (5-5-1909/19-8-1918) tal iniciativa, creación del Ilustre Colegio Provincial de Practicantes de Huelva, pero a buen seguro las gestiones se sucedieron arduamente y con anterioridad.

\section{FUENTES Y MÉTODO}

\section{Libro de Actas del Colegio de Practicantes de Sevilla 5-5-1909 - 19-8-1918}

Es un libro, tipo diario, con portada y contraportada de color azul y letras doradas que explicitan Colegio Provincial Practicantes Actas 5-5-1909-19-8-1918, encuadernación contemporánea, hojas de tamaño A4 cosidas en ramilletes, numeradas en vértice superior derecho, con renglón y margen izquierdo, amarillentas y con manchas atribuibles al óxido y al paso inexorable del tiempo y con textos en caligrafía de época en diversos colores. En su primera página se constata el siguiente texto: Don Vicente Ruiz de Cepeda Practicante en Medicina y Cirugía. Secretario del Colegio Provincial de Practicantes de Sevilla. Certifico: que este libro de actas tiene cuatrocientos folios y empieza en la sesión del día once de mayo de mil novecientos nueve. Sevilla 5 de mayo de 1909.

\section{RESULTADOS Y SU DISCUSIÓN}

\section{Análisis del Acta}

Aquel día, la primera pagina de los principales periódicos nacionales informaba a la sociedad madrileña del viaje de los Reyes de Inglaterra al País de Gales (ABC, 1912), a la sociedad barcelonesa sobre necrológicas del día y anuncios varios (La Vanguardia, 1912), mientras que la sociedad onubense era regida por el Alcalde D. Francisco García Ortiz (13/12/1911-22/9/1913). La sesión colegial que nos ocupa tuvo lugar en el local de la Real Academia de Medicina de Sevilla, en su primera sede (1895-1932), sita concretamente en el número 12 de la calle Alfonso XII, en pleno centro de la capital hispalense y que también albergó en sus inicios al Colegio de Practicantes, de Odontólogos y la Escuela de Matronas (Lupión, 1995). A esta sesión ordinaria asistieron un total de 8 miembros, 5 más no asistieron pero se excusaron y 9 miembros más ni asisten ni se excusan por lo que se hace constar la aplicación del artículo número 34 -contribución con donativos-, en cuanto a la no asistencia a las sesiones colegiales. Entre los asistentes figuran D. Pablo de Pablos Leal, Presidente, D. Antonio Matamoros Moreno, D. Antonio Moreno Pérez, D. José León Ríos, D. Miguel León Rodríguez, D. Manuel López Lara, D. José García Leanez y D. Luis Cledera 
Choclan. Respecto a los asuntos abordados en esta sesión, se inicia tal como es pertinente con la aprobación del Acta de la general anterior y de la directiva última. A continuación se contempla cómo favorable la solicitud de ingreso en la institución colegial suscrita el 12 de Junio de 1912 por D. Fernando Gayoso Fernández, a la postre Presidente del Colegio sevillano (Enero, 1918-Agosto, 1918). Después se contempla un balance económico interno que hace constar en caja un total de 196,60 ptas., de las de la época, dinero por entonces fabricado en la casa londinense Bradbury Wilkinson and Company, en los billetes -figuras femeninas en anverso y escudo de España y monumentos en reverso-, y en las monedas de plata y cobre -efigie del monarca Alfonso XIII- (Calicó, 2008). A continuación se identifican los colegiados que son cesados de la institución colegial por falta de pago en las cuotas colegiales, aspecto este nada extraño pues se sucede con bastante asiduidad en la época y aunque en ningún caso se explicitan los motivos, detrás tal proceder pudieran estar penurias personales, compromiso débil con el ente colegial etc., aunque también es cierto que las readmisiones tiempo después son frecuentes igualmente. Es a continuación cuando el Acta hace constar el fin último de esta investigación, el de la propuesta del Señor Secretario, D. Miguel León Rodríguez en la que se acuerda nombrar delegado de este Colegio a D. Marciano Gómez García, practicante en Sotiel Coronada para que gestione entres sus compañeros de Huelva la creación de un Colegio profesional. Es oportuno recordar en este instante y en cuánto a nuestros orígenes colegiales, la constancia documental de tres intentos de fundación del Colegio de Practicantes de Huelva, el primero acaeció en 1912 -no consolidado-, el segundo en el año 1918 -disuelto-, y el tercer y último intento en el año 1924 (Toscano, 2003). La sesión finaliza con el recordatorio a los asistentes de la entrada en vigor del artículo número 34 y 55 del Reglamento en cuánto a socorros se refiere.

\section{CONCLUSIONES}

Para finalizar este artículo, comentar que respecto a la investigación en Historia de la Enfermería y Colegial en Huelva, hasta este momento, lo expuesto, a partir de ahora, lo que nos propongamos...con trabajo y esfuerzo mantenido...un gesto simple en los inicios, una constancia en el tiempo y de una transcendencia inigualable para la Historia Colegial Enfermera Onubense.

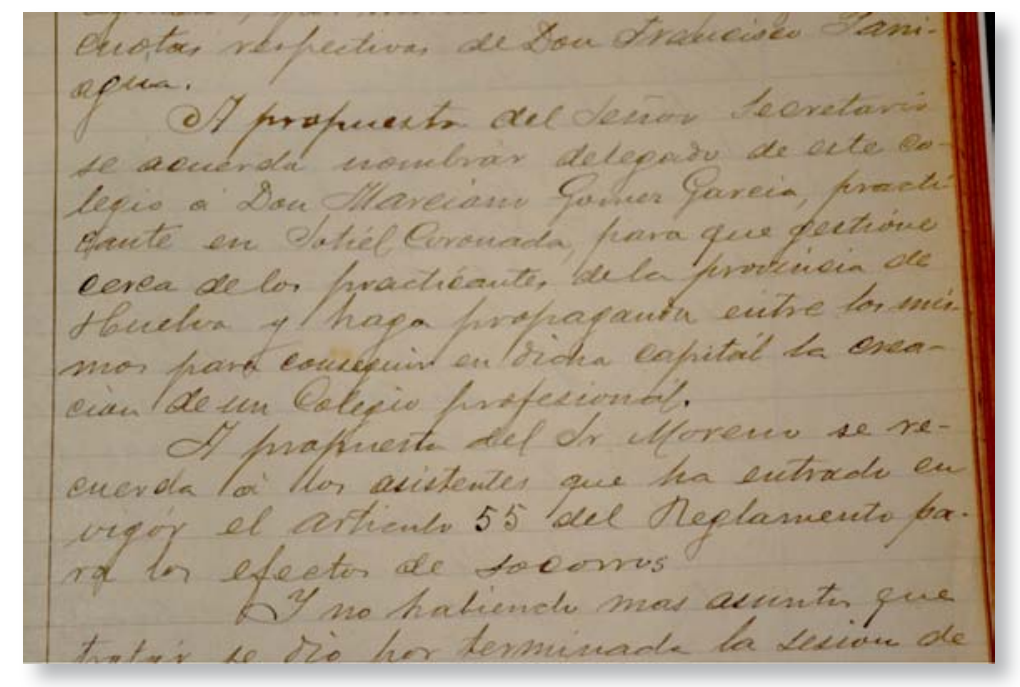

Ilustración no 1. Párrafo del Acta del Colegio Provincial de Practicantes de Sevilla. 1.7.1912, pág. 131. 


\section{REFERÊNCIAS}

- ABC. (1912) Diario Ilustrado. Año VIII. Na 2575. 2a Época. $1 / 7 / 1912$. Madrid

- Calicó, X. (2008) Numismática Española (1474-2001). Barcelona

- Gallardo, C. (1999) Marciano Gómez, en 1912, funda el Colegio de Practicantes de Huelva. Documentos de Enfermería 12,8

- Gallardo, C. (1993) La Enfermería Sevillana. El colegio y su historia 1900-1930. Colegio Oficial de Enfermería de Sevilla. Sevilla

- Libro de Actas del Colegio Provincial de Practicantes de Sevilla (5-5-1909/19-8-1918). Ilustre Colegio Oficial de Enfermería de Sevilla. Sevilla

- La Vanguardia. Diario Independiente de Barcelona. Año XXXI. No 14214 . 1/7/1912. Barcelona

- Lupión, E. (1995) El Real e Ilustre Colegio Oficial de Médicos de Sevilla. Historia viva de una institución secular. Colegio Médicos de Sevilla. Sevilla
- Oguisso, T. (2012) La incidencia del Consejo Internacional de Enfermeras en la historia y socialización de la Enfermería. Cultura de los Cuidados 32, 23-37

- Ruiz, Ma. D. (2011). Los antecedentes a la colegiación obligatoria de las matronas en Madrid. Cultura de los Cuidados 31, 69-76

- Ruiz, Ma . D. (2012) La tradición obstétrica familiar en el Real Colegio de Cirugía de San Carlos de Madrid: Concepción de Navas, la hija de Juan de Navas. Cultura de los Cuidados 32, 76-81

- Toscano, M. (2003) La fundación de los colegios y la sociedad española de principios del siglo XX. Documentos de Enfermería 21, 8-9

- Velandia, A.L. (2009) La Escuela Nacional Superior de Enfermeras de Colombia. Relaciones con Organismos Interamericanos. Cultura de los Cuidados 25, 36-45 